\title{
BISEPARATING MAPS BETWEEN SMOOTH VECTOR-VALUED FUNCTIONS ON BANACH MANIFOLDS
}

\author{
CHING-JOU LIAO AND YA-SHU WANG
}

\begin{abstract}
An $\mathscr{S}$-category consists all Banach manifolds as objects and subclasses of continuous functions (with some kind of smoothness) as morphisms. This notion covers, for example, the categories $C^{\infty}, C^{n}, C$, and Liploc of all smooth functions, $C^{n}$-functions, continuous functions, and local Lipschitz functions. It is shown by Garrido, Jaramillo and Prieto in 2000 that two $C^{\infty}$ smooth Banach manifolds $X$ and $Y$ are $C^{\infty}$-diffeomorphic to each other if and only if there is an algebra isomorphism from $C^{\infty}(X, \mathbb{R})$ onto $C^{\infty}(Y, \mathbb{R})$. We extend this result to general abstract $\mathscr{S}$-categories, and from algebra isomorphisms of scalar functions to the maps which are linear, bijective and separating, between vector-valued functions.
\end{abstract}

Mathematics subject classification (2010): 46E40, 58B10, 47B33, 47B38.

Keywords and phrases: $\mathscr{S}$-category, separating map, smooth functions, Lipschitz function.

\section{REFERENCES}

[1] Y. A. Abramovich, it Multiplicative representation of disjointness preserving operators, Indag. Math. 45, 3 (1983), 265-279.

[2] J. ARAujo, Separating maps and linear isometries between some spaces of continuous functions, J. Math. Anal. Appl. 226 (1998), 23-39.

[3] J. ARaujo, Realcompactness and spaces of vector-valued functions, Fund. Math. 172 (2002), 27-40.

[4] J. ARAUJO, Linear biseparating maps between spaces of vector-valued differentiable functions and automatic continuity, Advances in Math. 187 (2004), 488-520.

[5] J. Araujo And L. Dubarbie, Biseparating maps between Lipschitz function spaces, J. Math. Anal. Appl. 357 (2009), 191-200.

[6] J. Araujo And K. Jarosz, Automatic continuity of biseparating maps, Studia Math. 155 (2003), 231-239.

[7] W. ARENDT, Spectral properties of Lamperti operators, Indiana Univ. Math. J. 32 (1983), 199-215.

[8] R. Bonic AND J. Frampton, Smooth functions on Banach manifolds, J. of Math. Mech. 15 (1966), $877-898$.

[9] J. T. CHAN, Operators with the disjoint support property, J. Operator Theory 24 (1990), 383-391.

[10] L. Dubarbie, Separating maps between spaces of vector-valued absolutely continuous functions, Canad. Math. Bull. 53, 3 (2010), 466-474.

[11] J. J. FONT AND S. HERNŚANDEZ, On separating maps between locally compact spaces, Arch. Math. (Basel) 63 (1994), 158-165.

[12] M. I. GARrido AND J. A. JARAmillo, Variations on the Banach Stone theorem, Extracta Math. 17 (2002), 351-383.

[13] M. I. Garrido, J. A. Jaramillo And Á. Prieto, Banach-Stone theorems for Banach manifolds, Rev. R. Acad. Cienc. Exactas Fis. Nat. (Esp.) 94 (2000), 525-528.

[14] H.-L. GAU, J.-S. JEANG AND N.-C. WONG, Biseparating linear maps between continuous vectorvalued function spaces, J. Aust. Math. Soc. 74 (2003), 101-109.

[15] L. Gillman AND M. JeRISON, Rings of Continuous Functions, Van Nostrand, Princeton, NJ, 1960 
[16] J. M. Gutiérrez And J. G. Llavona, Composition operators between algebras of differentiable functions, Trans. Amer. Math. Soc. 338 (1993), 769-782.

[17] S. HeRnÁNDEZ, E. BECKENSTEIn AND L. NARICI, Banach-Stone theorems and separating maps, Manuscripta Math. 86 (1995), 409-416.

[18] K. JAROSZ, Automatic continuity of separating linear isomorphisms, Canad. Math. Bull. 33 (1990), 139-144.

[19] J.-S. JeAng And N.-C. Wong, Weighted composition operators of $C_{0}(X)$ 's, J. Math. Anal. Appl. 201 (1996), 981-993.

[20] A. Jiménez-Vargas, Moisés Villegas-Vallecillos And Y.-S. Wang, Banach-Stone theorems for vector-valued little Lipschitz, functions, Publ. Math. Debrecen 74 (2009), 81-100.

[21] A. JiMÉNEZ-VARGAS AND Y.-S. WANG, Linear biseparating maps between vector-valued little Lipschitz function spaces, Acta Math. Sin. (Engl. Ser.) 26 (2010), 1005-1018.

[22] A. Kriegl and P. W. Michor, The Convenient Setting of Global Analysis, American Mathematical Society, 1997.

[23] D. H. LeUnG, Biseparating maps on generalized Lipschitz spaces, Studia Math. 196 (2010), 23-40.

[24] D. H. Leung And Y.-S. WAng, Local operator on $C^{p}$, J. Math. Anal. Appl. 381 (2011), 308-314.

[25] L. NARICI AND E. Beckenstein, The separating map: a survey, Rend. Circ. Mat. Palermo (2) Suppl. 52 (1998), 637-648.

[26] C. H. Scanlon, Rings of functions with certain Lipschitz properties, Pacific J. Math. 32 (1970), 197-201. 